Article

\title{
Enzyme-Assisted Extraction Optimization, Characterization and Antioxidant Activity of Polysaccharides from Sea Cucumber Phyllophorus proteus
}

\author{
Yujing Qin ${ }^{1,+}{ }^{(\mathbb{D}}$, Qingxia Yuan ${ }^{1,+}{ }^{+}$, Yuexing Zhang ${ }^{1}$, Jialu Li ${ }^{1}$, Xinjiao Zhu ${ }^{1}$, Lingling Zhao ${ }^{1}$, \\ Jing Wen ${ }^{2}$, Jikai Liu ${ }^{1}$, Longyan Zhao ${ }^{1, *(1)}$ and Jinhua Zhao ${ }^{1,3, *}$ \\ 1 School of Pharmaceutical Sciences, South-Central University for Nationalities, Wuhan 430074, China; \\ 15927271905@163.com (Y.Q.); qingxiayuan@mail.scuec.edu.cn (Q.Y.); zhangyx88@csu.edu.cn (Y.Z.); \\ lijialu@tongji.edu.cn (J.L.); zhu162164131@163.com (X.Z.); 15035297217@163.com (L.Z.); \\ liujikai@mail.scuec.edu.cn (J.L.) \\ 2 College of Life Science and Technology, Lingnan Normal University, Zhanjiang 524048, China; \\ jw82123@126.com \\ 3 State Key Laboratory of Phytochemistry and Plant Resources in West China, Kunming Institute of Botany, \\ Chinese Academy of Sciences, Kunming 650201, China \\ * Correspondence: zhaolongyan@mail.scuec.edu.cn (L.Z.); zhaojinhua@mail.scuec.edu.cn (J.Z.) \\ + These authors contributed equally to this work.
}

Received: 23 January 2018; Accepted: 4 March 2018; Published: 6 March 2018

\begin{abstract}
Enzyme-assisted extraction optimization, characterization and in vitro antioxidant activity of polysaccharides from sea cucumber Phyllophorus proteus (PPP) were investigated in the present study. The optimal extraction conditions with a yield of $6.44 \pm 0.06 \%$ for PPP were determined as follows: Extraction time of $2.89 \mathrm{~h}$, ratio of extraction solvent to raw material of $16.26 \mathrm{~mL} / \mathrm{g}$, extraction $\mathrm{pH}$ of 6.83 , exraction temperature of $50{ }^{\circ} \mathrm{C}$ and papain concentration of $0.15 \%$. Three purified fractions, PPP-1a, PPP-1b and PPP-2 with molecular weights of 369.60, 41.73 and $57.76 \mathrm{kDa}$, respectively, were obtained from PPP by chromatography of FPA98Cl and Sepharose CL-6B columns. Analysis of monosaccharide compositions showed that PPP-1a consisted of $N$-acetyl-galactosamine (GalNAc), galactose (Gal) and fucose (Fuc), PPP-1b of Fuc as the only monosaccharide and PPP-2 of glucuronic acid, GalNAc and Fuc. Sulfate contents of PPP, PPP-1a, PPP-1b and PPP-2 were determined to be $21.9 \%, 20.6 \%, 25.2 \%$ and $28.0 \%(w / w)$, respectively. PPP and PPP-1a had higher molecular weight and intrinsic viscosity than those of the PPP- $1 b$ and PPP-2. PPP, PPP- $1 a$, PPP- $1 b$ and PPP-2 exhibited obvious activities of scavenging 1,1-diphenyl-2-picrylhydrazyl radical, hydroxyl radical, superoxide radical and ABTS radical in different extent, which suggested that the polysaccharides from Phyllophorus proteus may be novel agents having potential value for antioxidation.
\end{abstract}

Keywords: sea cucumber; polysaccharide; enzyme-assisted extraction; characterization; antioxidant activity

\section{Introduction}

Sea cucumbers belong to Echinodermata, Holothuroidea, and are important marine invertebrates found in most benthic marine habitats and deep seas across the world [1]. These animals have been a traditional tonic food and folk medicine in many countries for centuries and have gained increasing interest among researchers in recent years for their health benefits and diverse biological activities including anticancer, anti-diabetes, anti-inflammation, anti-obesity, immunomodulatory activity and anti-atherosclerosis [2-5]. These biofunctions of sea cucumbers can be attributed to 
their series of bioactive compounds such as triterpenes, lactones, cerebrosides, organic acids and polysaccharides [6-8].

Polysaccharides from sea cucumber, as one of its main components, can be divided into two main types, i.e., fucosylated glycosaminoglycan and sulfated fucoidan $[9,10]$. These biological macromolecules have shown multiple pharmacological activities such as anti-hyperlipidemia, anti-hyperglycemia, antitumor, antivirus, anti-inflammation, anticoagulation and antithrombosis, and may therefore serve as promising agents for some disease treatment and prophylaxis [11-14]. There are different techniques to extract the polysaccharides such as hot water extraction, microwave-assisted extraction, ultrasound-assisted extraction, and enzyme-assisted extraction $[15,16]$. Compared with other strategies, enzyme-assisted extraction has the advantage of being easily operated, highly efficient, environmentally friendly, and easily keeping structure of polysaccharides [17]. Enzymes can effectively lyse cells, to release the bioactive components contained inside the cells. Thus, the enzyme-assisted extraction technology has been widely used in natural product extraction. Particularly, in previous studies, researchers found that papain, a cysteine protease, can be applied to release polysaccharides from the proteoglycans in body wall of sea cucumbers $[10,13]$. However, as for enzyme-assisted extraction of the polysaccharides from sea cucumber, the optimum extraction conditions such as the optimal reaction temperature, extraction time, $\mathrm{pH}$, enzyme concentration and ratio of solvent to raw material are still unclear. Therefore, to extract the polysaccharides efficiently, optimization of the extraction conditions is necessary. The response surface methodology (RSM) is a robust method for optimization of extraction of various active substances and has been used to optimize the extraction conditions of many polysaccharides derived from different species of plant, animal and fungus for its less laborious and time-consuming advantages than other methods [15-17]. This method may also be used for optimization of the enzyme-assisted extraction conditions of polysaccharides from sea cucumber.

The polysaccharides from various sea cucumber species have obviously distinctive structures such as sulfate substitution patterns and monosaccharide proportions, and different physicochemical characteristics $[18,19]$. Some uncommon sea cucumber species remain to be studied, one of which is Phyllophorus proteus, a seafood consumed in China. The anticoagulant and antithrombotic activities of sea cucumber polysaccharides have been extensively studied, whereas, their antioxidant activities activity is rarely investigated [14]. It was reported that the extracts from Parastichopus tremulus and Holothuria forskali and the crude polysaccharides from Apostichopus japonicas had anti-oxidant activity [20-22]. While little information on the polysaccharides from sea cucumber Phyllophorus proteus (PPP) is available. Therefore, to study the structural characteristic of PPP and their antioxidant activities may be worthy to expand the knowledge and possible application of sea cucumber polysaccharides.

In the present study, we report here the results of enzyme-assisted extraction optimization, the physicochemical characteristics and in vitro antioxidant activity of PPP. RSM was employed to optimize the extraction conditions, and PPP were prepared by the optimal conditions selected. The purified fractions isolated from PPP were then characterized via chemical analysis, chromatography and spectroscopy methods. Finally, the antioxidant activities of PPP and its purified fractions were investigated.

\section{Materials and Methods}

\subsection{Materials and Chemicals}

The dry sea cucumber Phyllophorus proteus was collected from Zhanjiang City (Guangdong, China), and identified by one of coauthors, professor Wen using the mitochondrial cytochrome oxidase I (COI) gene as molecular marker [23]. The partial COI gene sequence of the collected sea cucumber determined was: ATAATGATTAAGAGGATTTGGAAACTGACTTATCCCATTAATGATAGGAG CCCCAGATATGGCTTTTCCCCGAATGAAAAAAATGAGATTCTGACTAGTTCCCCCATCCTTTATC TTACTATTAGCCTCAGCTGGTGTAGAAAGAGGAGTAGGAACAGGATGAACAATATATCCACCC TTATCAAGAAAAATTGCTCATGCAGGAGGATCCGTCGATCTTGCCATTTTCTCTCTCCACCTAG 
CAGGAGCCTCATCAATCCTAGCCTCAATAAACTTCATCACCACCATAATAAAAATGCGATCCCC AGGAATTAGATTTGATCGCCTACCACTATTCATCTGATCAGTCTTCATAACAGCTTTCCTCCTCCT CCTAAGACTACCAGTCCTAGCAGGAGCCATAACTATGCTTCTAACCGACCGAAAAATCAAAAC AACATTCTTTGACCCCTCAGGAGGAGGAGATCCTATACTATTTCAACACCTATTCTGATTCTTTG GACACCCAGAAGTCTACATTCTTATCCTACCAGGATTCGGAATGATATCCCACATAGTTGCCCAC TACAGCGGAAAGCAAGAACCCTTCGGATATCTAGGAATGGTCTACGCAATGGTAGCCATTGGCA TTTTAGGCTTCCTTGTATGAGCACACCACATGTTTACTGTTGGAATGGATGTAGCAACCACGAGCA. The homogeny between this sequence and the known sequence of Phyllophorus proteus in the international Bio-barcode System (BOLD SYSTEMS) was up to $99 \%$.

Amberlite FPA98Cl was obtained from H\&E Co., Ltd. (Beijing, China). Sepharose CL-6B was purchased from GE Healthcare Life Sciences (Uppsala, Sweden). Papain $(800 \mathrm{U} / \mathrm{mg}$ ) was purchased from Shanghai Yuanye Bio-Technology Co., Ltd. (Shanghai, China). Standard D-series Dextrans (D-2, 3, 4, 5, 6, 7 and 8) were obtained from National Institutes for Food Drug Control (Beijing, China). L-Rhamnose (Rha), D-galactose (Gal), D-galacturonic acid (GalA), D-glucose (Glc), D-glucuronic acid (GlcA), 3-methyl-1-phenyl-2-pyrazolin-5-one (PMP), 1,1-diphenyl-2-picrylhydrazyl (DPPH), ascorbic acid $(\mathrm{Vc})$, phenazine methosulphate (PMS), nitroblue tetrazolium (NBT), reduced nicotinamide adenine dinucleotide (NADH) and [2,2'-azinobis-(3-ethyl-benzothiazolin-6-sulfonic acid)] diammonium salt (ABTS) were purchased from Sigma Chemical Co. (St. Louis, MO, USA). D-Mannose (Man), L-arabinose (Ara), D-ribose (Rib), D-xylose (Xyl), N-acetyl-galactosamine (GalNAc) and L-fucose (Fuc) were purchased from Aladdin Chemical Reagent Co., Ltd. (Shanghai, China). All other chemicals used were of analytical grade.

\subsection{Extraction of Polysaccharides}

The dry sea cucumbers were further dried by hot air at $60^{\circ} \mathrm{C}$ for $24 \mathrm{~h}$, ground into fine powder and sieved through a 60-mesh sieve to obtain sea cucumber powder. Five grams of the dried powder was used in each extraction process, and extracted under experimental condition. After extraction, the suspension was adjusted to $\mathrm{pH} 2.8$ by $1 \mathrm{M} \mathrm{HCl}$, kept at $4{ }^{\circ} \mathrm{C}$ for $4 \mathrm{~h}$ and centrifuged at $7441 \times g$ for $20 \mathrm{~min}$ to remove acidic protein. The supernatant was neutralized with $1 \mathrm{M} \mathrm{NaOH}$, mixed with a triple volume of absolute ethanol and kept at $4{ }^{\circ} \mathrm{C}$ for $4 \mathrm{~h}$. The precipitates were collected by centrifugation at $4816 \times g$ for $15 \mathrm{~min}$ and freeze-dried to obtain PPP. The extraction yield was calculated by the following formula:

Extraction yield $(\%)=W_{1} / W_{0} \times 100$, where $W_{1}$ and $W_{0}$ are the weights of PPP and the dried sea cucumber sample respectively.

\subsection{Experimental Design of RSM}

To optimize the production of PPP, extraction conditions that may affect its extraction yield such as temperature, extraction time, $\mathrm{pH}$, enzyme concentration of papain and ratio of extraction solvent to raw material were investigated using single-factor test method. At the beginning of the single-factor tests, temperature, extraction time, $\mathrm{pH}$, enzyme concentration and ratio of extraction solvent to raw material were set at $50{ }^{\circ} \mathrm{C}, 6 \mathrm{~h}, 6.5,0.2 \%$, and $15 \mathrm{~mL} / \mathrm{g}$, respectively, according to our previous study [10]. The experimental conditions were the same in each test except the investigated factor, which was changed. On the basis of the single factor experiments, the factors having significant impact on PPP yield were screened out for the response surface experiments. The three factors chosen in our present study were the ratio of extraction solvent to raw material ( $\mathrm{mL} / \mathrm{g}$ ), extraction time $(\mathrm{h})$ and extraction $\mathrm{pH}$, which were designated as $\mathrm{X}_{1}, \mathrm{X}_{2}$ and $X_{3}$, and prescribed into three levels, coded $-1,0$, and +1 for low, middle and high value, respectively (Table 1). The test variables were coded according to the following Equation (1):

$$
X_{i}=\frac{\chi_{i}-\chi_{0}}{\Delta \chi_{i}}
$$

where $X_{\mathrm{i}}$ and $\chi_{i}$ are the coded and actual value of the independent variable, respectively, $\chi_{0}$ is the actual value of the independent variable at the central point, and $\Delta \chi_{i}$ is the step change of the variable. 
Table 1. Independent variables and their levels used for Box-Behnken design (BBD).

\begin{tabular}{ccccc}
\hline \multirow{2}{*}{ Factors } & & \multicolumn{3}{c}{ Levels and Range } \\
\cline { 3 - 5 } & Code & $\mathbf{- 1}$ & $\mathbf{0}$ & $\mathbf{1}$ \\
\hline A: ratio of extraction solvent to raw material $(\mathrm{mL} / \mathrm{g})$ & $X_{1}$ & 10 & 15 & 20 \\
B: extraction time $(\mathrm{h})$ & $X_{2}$ & 1.5 & 2.5 & 3.5 \\
C: extraction $\mathrm{pH}$ & $X_{3}$ & 5 & 6 & 7 \\
\hline
\end{tabular}

The extraction yield of PPP was defined as the dependent variable. The Box-Behnken design consisted of 17 experimental points, each of which was carried out in triplicate in a random order.

To predict the optimal point, a quadratic polynomial model was fitted to correlate relationship between the independent variables and response (PPP yield), as shown below Equation (2):

$$
Y=\beta_{0}+\sum_{i=1}^{3} \beta_{i} X_{i}+\sum_{i=1}^{3} \beta_{i i} X_{i}^{2}+\sum_{i=1}^{2} \sum_{j=i+1}^{3} \beta_{i j} X_{i} X_{j}
$$

where $Y$ is the response variable (extraction yield of PPP); $\beta_{0}, \beta_{i}, \beta_{i i}$ and $\beta_{i j}$ are the regression coefficients of variables for intercept, linear, quadratic and interaction terms, respectively; $X_{\mathrm{i}}$ and $X_{\mathrm{j}}$ are the independent variables $(i \neq j)$.

\subsection{Isolation of Homogeneous Polysaccharides from PPP}

PPP was dissolved in deionized water and loaded onto an FPA98Cl column $(4.0 \times 50 \mathrm{~cm})$. Then, the column was stepwise eluted with $0,0.5,1.0,1.5$ and $2.0 \mathrm{M}$ sodium chloride $(\mathrm{NaCl})$ solution at a flow rate of 2 (BV) /h. Then obtained fraction PPP-1 or PPP-2 was loaded onto a Sepharose CL-6B column $(2.0 \times 150 \mathrm{~cm})$ and eluted with $0.2 \mathrm{M} \mathrm{NaCl}$ aqueous solution at a flow rate of $15 \mathrm{~mL} / \mathrm{h}$. The eluents were collected $(10 \mathrm{~mL} /$ fraction) with an automatic fraction collector. Three completely separated fractions, PPP-1a, PPP-1b and PPP-2, were collected by checking the absorbance at $490 \mathrm{~nm}$ using phenol-sulphuric acid method [24], dialyzed against distilled water for 3 days with a dialysis membrane (molecular weight cut-off of $3500 \mathrm{Da}$ ) and lyophilized.

\subsection{Characterization of $P P P, P P P-1 a, P P P-1 b$ and $P P P-2$}

\subsubsection{Determination of Homogeneity and Molecular Weight}

The homogeneity and molecular weight of PPP, PPP-1a, PPP-1b and PPP-2 were examined by high-performance gel permeation chromatography (HPGPC) using an Agilent 1260 series apparatus (Agilent Technologies, Santa Clara, CA, USA) equipped with a RID detector and a Shodex OH-pak SB-804 HQ or Shodex OH-pak SB-806 HQ column $(8 \mathrm{~mm} \times 300 \mathrm{~mm})$. The column was eluted with $0.1 \mathrm{M} \mathrm{NaCl}$ solution at a flow rate of $0.5 \mathrm{~mL} / \mathrm{min}$ at $35^{\circ} \mathrm{C}$. The HPLC system was calibrated by D-series dextran standards (D-2, D-3, D-4, D-5, D-6, D-7 and D-8) [9].

\subsubsection{Analysis of Monosaccharide Composition, Protein and Sulfate Content}

The monosaccharide compositions of PPP, PPP-1a, PPP-1b and PPP-2 were analyzed according to the reported method [15] with some modifications. Briefly, the monosaccharide standards and polysaccharide solution $(100 \mu \mathrm{L}, 5 \mathrm{mg} / \mathrm{mL})$ were hydrolyzed with $100 \mu \mathrm{L}$ of $4 \mathrm{M}$ trifluoroacetic acid (TFA) at $110{ }^{\circ} \mathrm{C}$ for $4 \mathrm{~h}$ under the nitrogen environment. After removing the excess TFA, the hydrolysate was labeled with PMP and analyzed by an Agilent 1260 HPLC system equipped with a DAD detector and an Eclipse Plus C18 column ( $4.6 \times 250 \mathrm{~mm}, 5 \mu \mathrm{m}$, Agilent). The injection volume was $20 \mu \mathrm{L}$, the mobile phase was a mixture of phosphate buffered saline (PBS, $0.1 \mathrm{M}, \mathrm{pH}$ 6.7) and acetonitrile in a ratio of 83: $17(v / v)$, column temperature was $30^{\circ} \mathrm{C}$, flow rate was $1.0 \mathrm{~mL} / \mathrm{min}$, and detector wavelength was $245 \mathrm{~nm}$. 
The protein content was measured by the Bradford analysis, as previous study [15]. The content of sulfate radical was determined according to the $\mathrm{BaCl}_{2}$ /gelatin method as described previously [25]. The $\mathrm{SO}_{3}{ }^{-}$to $\mathrm{COO}^{-}$molar ratios of the polysaccharides were determined by a conductimetric titration method [26].

\subsubsection{NMR Analysis}

All purified fractions were dissolved in deuterium oxide $\left(\mathrm{D}_{2} \mathrm{O}, 99.9 \% \mathrm{D}\right)$ and lyophilized three times to replace exchangeable protons with $\mathrm{D}_{2} \mathrm{O}$. The lyophilized samples were then dissolved in $\mathrm{D}_{2} \mathrm{O}$ at a concentration of $40 \mathrm{mg} / \mathrm{mL}$. NMR analyses were performed at $298 \mathrm{~K}$ with a $600 \mathrm{MHz}$ Bruker Advance spectrometer (Zurich, Switzerland) in the FT mode as described previously [27].

\subsubsection{Specific Rotation, Intrinsic Viscosity and FT-IR Spectrometric Analysis}

The specific rotation of the polysaccharides was detected by a polarimeter at the concentration of $2 \mathrm{mg} / \mathrm{mL}$ at $20^{\circ} \mathrm{C}$. The intrinsic viscosity [ $\eta$ ] was determined in a $0.1 \mathrm{M} \mathrm{NaCl}$ solution at $25^{\circ} \mathrm{C}$ using an Ubbelohde-type capillary viscometer according to the method in Pharmacopoeia of the People's Republic of China [28]. The purified fractions PPP-1a, PPP-1b and PPP-2 were mixed with spectroscopic-grade potassium bromide powder, ground and pressed into pellets for FT-IR measurement. FT-IR spectra were recorded on a Bruker Tensor 27 infrared spectrometer (Ettlingen, Germany) at the frequency range of $4000-400 \mathrm{~cm}^{-1}$.

\subsection{Assay of In Vitro Antioxidant Activities}

\subsubsection{Assay of DPPH Radical Scavenging Activity}

The DPPH radical scavenging activity of polysaccharide samples were carried out according to the method of previous report with slight modifications [29,30]. Briefly, PPP, PPP-1a, PPP-1b or PPP-2 solution was dissolved in deionized water at different concentrations $(0.25,0.5,1.0,2.0$, and $4.0 \mathrm{mg} / \mathrm{mL})$ and added into a 96-well plate ( $50 \mu \mathrm{L} /$ well). The $25 \mu \mathrm{L}$ of DPPH-ethanol solution $(0.4 \mathrm{mM})$ and $100 \mu \mathrm{L}$ of deionized water were then pipetted into each well. After reaction for $30 \mathrm{~min}$ at room temperature in the dark, the absorbance at $517 \mathrm{~nm}$ was detected by a microplate reader (BioTek Instruments Inc., Winooski, VT, USA). Vc was included as positive control. DPPH radical scavenging activity was calculated as Equation (3):

$$
\mathrm{DPPH} \text { radical scavenging activity }(\%)=\left[1-\left(\mathrm{A}_{1}-\mathrm{A}_{2}\right) / \mathrm{A}_{0}\right] \times 100
$$

where $A_{1}$ is the absorbance of the samples, $A_{2}$ is the absorbance of the samples under identical conditions as $A_{1}$ except without DPPH in the reaction system, and $A_{0}$ is the absorbance of the blank control (ultrapure water instead of sample).

\subsubsection{Assay of Hydroxyl Radical Scavenging Activity}

The reported method [31] with slight modifications was applied to detect the hydroxyl radical scavenging activities of PPP, PPP-1a, PPP-1b and PPP-2, compared with Vc. The reaction mixture was prepared by mixing several different reagents in sequence: $50 \mu \mathrm{L}$ of ferrosin $(0.75 \mathrm{mM}), 75 \mu \mathrm{L}$ of phosphate buffer (0.15 M, pH 7.4), $50 \mu \mathrm{L}$ of $\mathrm{FeSO}_{4}(0.75 \mathrm{mM}), 50 \mu \mathrm{L}$ of sample solution and $50 \mu \mathrm{L}$ of $\mathrm{H}_{2} \mathrm{O}_{2}$ $(0.01 \%, w / v)$. After $30 \mathrm{~min}$ of reaction at $37^{\circ} \mathrm{C}$, the absorbance of the mixture was measured at $536 \mathrm{~nm}$. The scavenging activity was calculated as Equation (4):

$$
\text { Hydroxyl radical scavenging activity }(\%)=\left[\left(\mathrm{A}_{2}-\mathrm{A}_{0}\right) /\left(\mathrm{A}_{1}-\mathrm{A}_{0}\right)\right] \times 100
$$

where $A_{2}$ is the absorbance of the sample, $A_{1}$ is the absorbance of reaction mixture using ultrapure water instead of $\mathrm{H}_{2} \mathrm{O}_{2}$ and sample, and $\mathrm{A}_{0}$ is the absorbance of the blank control (ultrapure water instead of sample). 


\subsubsection{Assay of Superoxide Radical Scavenging Activity}

The scavenging effects of polysaccharides on superoxide radical were determined by a method named PMS/NADH-NBT system as described previously [15,32] with some modifications. The mixtures contained $50 \mu \mathrm{L}$ of samples $(0.25-4.0 \mathrm{mg} / \mathrm{mL}), 50 \mu \mathrm{L}$ of NBT solution $(156 \mu \mathrm{M}), 50 \mu \mathrm{L}$ of NADH solution $(156 \mu \mathrm{M})$ and $50 \mu \mathrm{L}$ of PMS solution $(60 \mu \mathrm{M})$, were kept at $25^{\circ} \mathrm{C}$ for $5 \mathrm{~min}$. The absorbance was measured at $560 \mathrm{~nm}$ with ultrapure water as a blank control. Vc was used as positive control. The scavenging ability was calculated using the following Equation (5):

$$
\text { Scavenging rate }(\%)=\left[1-\left(\mathrm{A}_{1}-\mathrm{A}_{2}\right) / \mathrm{A}_{0}\right] \times 100
$$

where $A_{1}$ is the absorbance of various samples, $A_{2}$ is the background absorbance of the sample $(0.1 \mathrm{M}$ phosphate buffer instead of NBT solution), and $\mathrm{A}_{0}$ is the absorbance of the blank control (ultrapure water instead of sample).

\subsubsection{Assay of ABTS Radical Scavenging Activity}

The ABTS radical scavenging activities of PPP, PPP-1a, PPP-1b and PPP-2 were measured by ABTS radical cation decolorization assay according to the literature procedure $[33,34]$. Briefly, ABTS solution $(7 \mathrm{mM})$ was oxidized with potassium persulphate $(4.95 \mathrm{mM})$ in the dark at room temperature for $12 \mathrm{~h}$ and then diluted with PBS (0.2 M, pH 7.4) to produce an absorbance of $0.70 \pm 0.01 \mathrm{at} 734 \mathrm{~nm}$. $200 \mu \mathrm{L}$ of the resulting ABTS $^{+}$solution was then mixed with $20 \mu \mathrm{L}$ of sample solution and kept at room temperature for $6 \mathrm{~min}$, and the absorbance at $734 \mathrm{~nm}$ was determined. The ABTS radical scavenging activity was calculated as following Equation (6):

$$
\text { ABTS radical scavenging activity }(\%)=\left[1-\left(\mathrm{A}_{1}-\mathrm{A}_{2}\right) / \mathrm{A}_{0}\right] \times 100
$$

where $A_{1}$ is the absorbance of various samples, $A_{2}$ is the background absorbance of samples (PBS instead of $\mathrm{ABTS}^{+}$solution), and $\mathrm{A}_{0}$ is the absorbance of the blank control (ultrapure water instead of sample).

\subsection{Statistical Analysis}

The Design-Expert software version 8.0.6 (Stat-Ease, Inc., Minneapolis, MN, USA) was used for the experimental design and data analysis of RSM. The results of the antioxidant assay were reported as mean \pm SD of three replicates. Data were statistically analyzed by One-Way analysis of variance (ANOVA) procedure with SPSS software version 19.0 (IBM SPSS, Inc., Chicago, IL, USA), followed by the Duncan test. $P$-value of less than 0.05 was regarded as significance.

\section{Results and Discussion}

\subsection{Optimization of Extraction Parameters}

\subsubsection{Model Building and Statistical Analysis}

In our present study, five parameters including enzyme concentration, extraction temperature, extraction time, ratio of solvent to raw material and $\mathrm{pH}$ were picked out for investigating their influences on the PPP extraction yields. According to results of the single factor experiments in Figure 1, PPP extraction yield significantly increased $(p<0.05)$ from $3.14 \%$ to $5.93 \%$ as the enzyme concentration increased from $0.05 \%$ to $0.15 \%$ (Figure $1 \mathrm{~A}$ ). When the enzyme concentration continued to increase, the extraction yields had no obvious changes $(p>0.05)$. Therefore, $0.15 \%$ was chosen as the extracting enzyme concentration through all the extraction optimization experiments. The temperature $\left(30,40\right.$ and $\left.50{ }^{\circ} \mathrm{C}\right)$ (Figure 1B), ratio of solvent to raw material (5:1, 10:1, 15:1) (Figure 1C), pH (4, 5 and 6) (Figure 1D) and extraction time (0.5, 1.5 and $2.5 \mathrm{~h}$ ) (Figure 1E) affected the PPP extraction yields significantly $(p<0.05)$. Further increasing the level of these factors, the PPP yields decrease or 
increase sightly $(p>0.05)$. When temperature increased from 30 to $70{ }^{\circ} \mathrm{C}$, the PPP yields increased from $5.41 \%$ to $5.98 \%$. Taking into consideration that the effect of temperature was greatly inferior to that of other factors, extraction temperature was not considered in further RSM experiments. Therefore, the three factors, ratio of solvent to raw material, $\mathrm{pH}$, and time, were screened out for the response surface experiments.
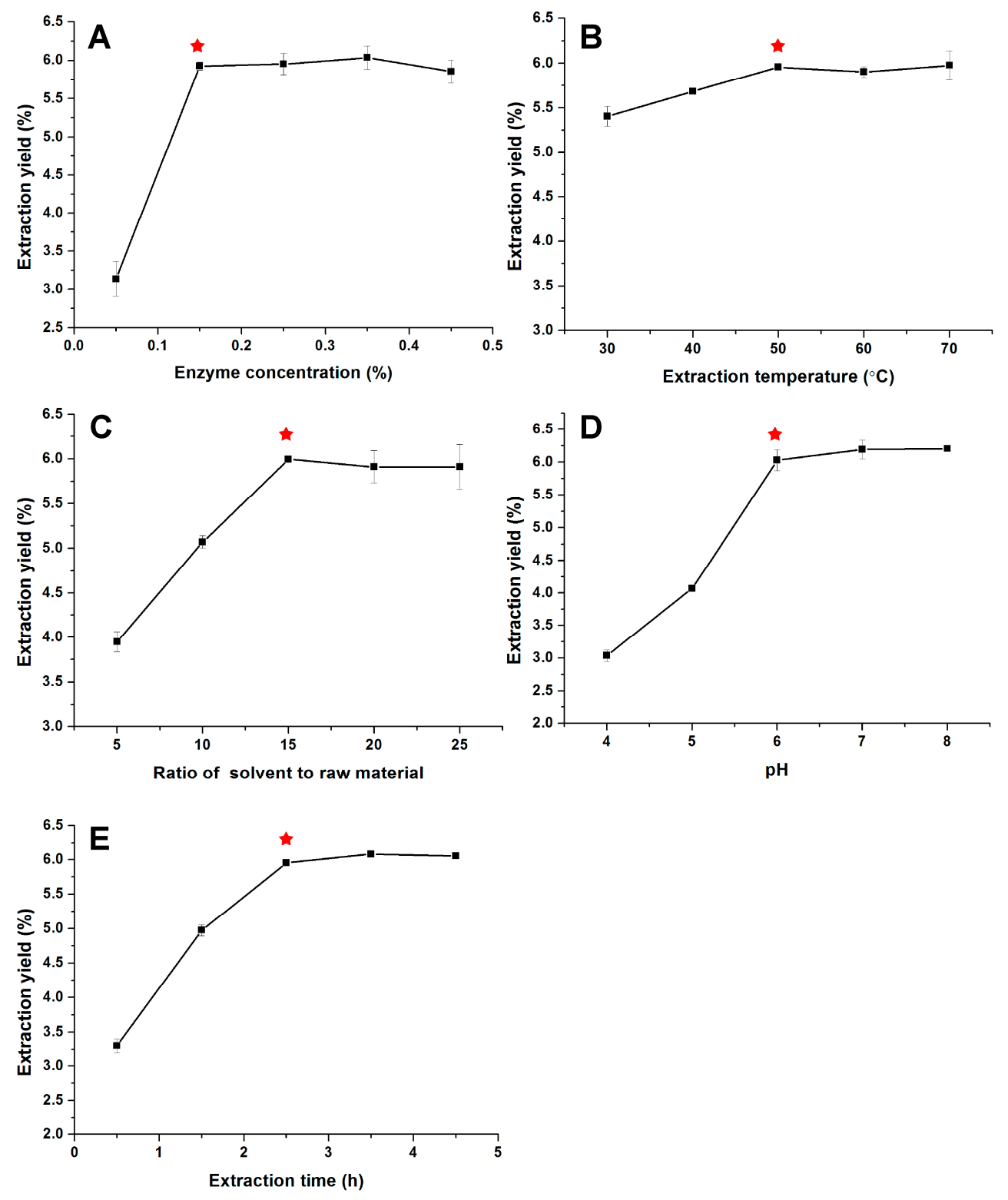

Figure 1. Effects of different extraction parameters such as enzyme concentration (A), temperature (B), ratio of solvent to raw material (C), $\mathrm{pH}(\mathbf{D})$, and time (E) on the yield of polysaccharides from sea cucumber Phyllophorus proteus. $\star$ indicates the optimal reaction condition for each single-factor test.

The results of the 17 runs including the design and experimental values in BBD design were listed in Table 2. The PPP yield and the test variables were related by the following second-order polynomial Equation (7):

$$
\begin{gathered}
Y=-59.32119+1.31749 X_{1}+5.04959 X_{2}+14.85909 X_{3}-0.037159 X_{1} X_{2}-0.019837 X_{1} X_{3} \\
-0.076665 X_{2} X_{3}-0.033252 X_{1}^{2}-0.68269 X_{2}{ }^{2}-1.10467 X_{3}{ }^{2}
\end{gathered}
$$


The analysis results of ANOVA, adequacy and fitness of the response surface quadratic model were shown in Table 3. The $F$-value $(49.15)$ and $P$-value $(<0.001)$ turned out that the model was highly significant. The lack of fit values of $F$ and $P$ were 0.013 and 0.9976 , respectively, indicating that the model fitted well. The determination coefficient $\left(R^{2}\right)$ and adjusted determination coefficient $\left(\right.$ adj- $\left.R^{2}\right)$ were further applied to check the goodness-of-fit of the model. The value of $R^{2}$ was 0.9844 , which meant that there was satisfactory correlation between actual and predicted values. The value of adj- $R^{2}$ was 0.9644 , which indicated that most variations ( $>96 \%$ ) of the extraction could be predicted by the model.

In general, a small $p$ value less than 0.05 indicated that the corresponding coefficient was significant. Accordingly, the independent variables $\left(X_{1}, X_{2}\right.$ and $\left.X_{3}\right)$ and all three quadratic terms $\left(X_{1}{ }^{2}\right.$, $X_{2}{ }^{2}$ and $\left.X_{3}{ }^{2}\right)$ can significantly $(p<0.001)$ affect the extraction yield of PPP.

Table 2. The Box-Behnken design matrix and the results of PPP extraction yield.

\begin{tabular}{ccccc}
\hline Experiment & $\begin{array}{c}\text { A: Ratio of Extraction Solvent to } \\
\text { Raw Material } \mathbf{( m L / g )}\end{array}$ & $\begin{array}{c}\text { B: Extraction } \\
\text { Time } \mathbf{( h )}\end{array}$ & $\begin{array}{c}\text { C: Extraction } \\
\mathbf{p H}\end{array}$ & $\begin{array}{c}\text { Yield } \\
\mathbf{( \% )}\end{array}$ \\
\hline 1 & -1 & -1 & 0 & 3.48 \\
2 & 1 & -1 & 0 & 4.97 \\
3 & -1 & 1 & 0 & 5.12 \\
4 & 1 & 1 & 0 & 5.86 \\
5 & -1 & 0 & -1 & 2.71 \\
6 & 1 & 0 & -1 & 3.95 \\
7 & -1 & 0 & 1 & 5.12 \\
8 & 1 & 0 & 1 & 5.97 \\
9 & 0 & -1 & -1 & 2.78 \\
10 & 0 & 1 & -1 & 4.15 \\
11 & 0 & -1 & 1 & 5.18 \\
12 & 0 & 1 & 1 & 6.24 \\
13 & 0 & 0 & 0 & 6.83 \\
14 & 0 & 0 & 0 & 6.03 \\
15 & 0 & 0 & 0 & 6.32 \\
16 & 0 & 0 & 0 & 6.56 \\
17 & 0 & 0 & 0 & 6.14 \\
\hline
\end{tabular}

Table 3. ANOVA for response surface quadratic model of PPP extraction.

\begin{tabular}{cccccc}
\hline Source & $\begin{array}{c}\text { Sum of } \\
\text { Squares }\end{array}$ & df & Mean Square & F-Value & $\boldsymbol{P}$-Value \\
\hline Model & 26.71 & 9 & 2.97 & 49.15 & $<0.0001^{* *}$ \\
$X_{1}$ & 2.33 & 1 & 2.33 & 38.63 & $0.0004^{* *}$ \\
$X_{2}$ & 3.08 & 1 & 3.08 & 50.93 & $0.0002^{* *}$ \\
$X_{3}$ & 9.95 & 1 & 9.95 & 164.72 & $<0.0001^{* *}$ \\
$X_{1} X_{2}$ & 0.14 & 1 & 0.14 & 2.33 & 0.1708 \\
$X_{1} X_{3}$ & 0.038 & 1 & 0.038 & 0.63 & 0.4535 \\
$X_{2} X_{3}$ & 0.024 & 1 & 0.024 & 0.40 & 0.5482 \\
$X_{1}{ }^{2}$ & 2.93 & 1 & 2.93 & 48.53 & $0.0002^{* *}$ \\
$X_{2}{ }^{*}$ & 1.97 & 1 & 1.97 & 32.65 & $0.0007^{* *}$ \\
$X_{3}{ }^{*}$ & 5.13 & 1 & 5.13 & 85.03 & $<0.0001^{* *}$ \\
Residual & 0.42 & 7 & 0.060 & & $0.9976^{\text {a }}$ \\
Lack of fit & 0.00415 & 3 & 0.001383 & 0.013 & \\
Pure error & 0.42 & 4 & 0.10 & \\
Cor Total & 27.13 & 16 & $R^{2}=0.9844 ;$ Adj $R^{2}=0.9644 ;$ Pred $R^{2}=0.9735$ & \\
\hline \multicolumn{5}{c}{ NS $=$ non-significant. ${ }^{* *} p<0.01}$. \\
\hline
\end{tabular}




\subsubsection{Optimization of Extraction Conditions of PPP and Validation of the Model}

The 3D response surface and 2D contour plots of the BBD were obtained using Design Expert software (Version 8.0.6). The responses of PPP yields to changes in ratio of extraction solvent to raw material $(\mathrm{mL} / \mathrm{g})$, extraction time $(\mathrm{h})$ and extraction $\mathrm{pH}$ were presented in Figure 2 . In the $3 \mathrm{D}$ response surface and 2D contour plots, the extraction yield of PPP was obtained along with two continuous variables, while the third variable was fixed at level 0 . It was obvious that when increased the three variables the PPP yield increased at first, and then gradually decreased. Additionally, the extraction $\mathrm{pH}$ had more significant impact on PPP yield than the ratio of extraction solvent to raw material and extraction time. These results were consistent with the ANOVA analysis.

The shapes of the contour plots can reflect the interaction effects between the variables. Elliptical contour plot indicated that the interactions of two independent variables were significant, while the circular contour plots were considered negligible [35-37]. According to Figure 2 and Table 3, the interactions between the variables were not significant $(p>0.05)$.
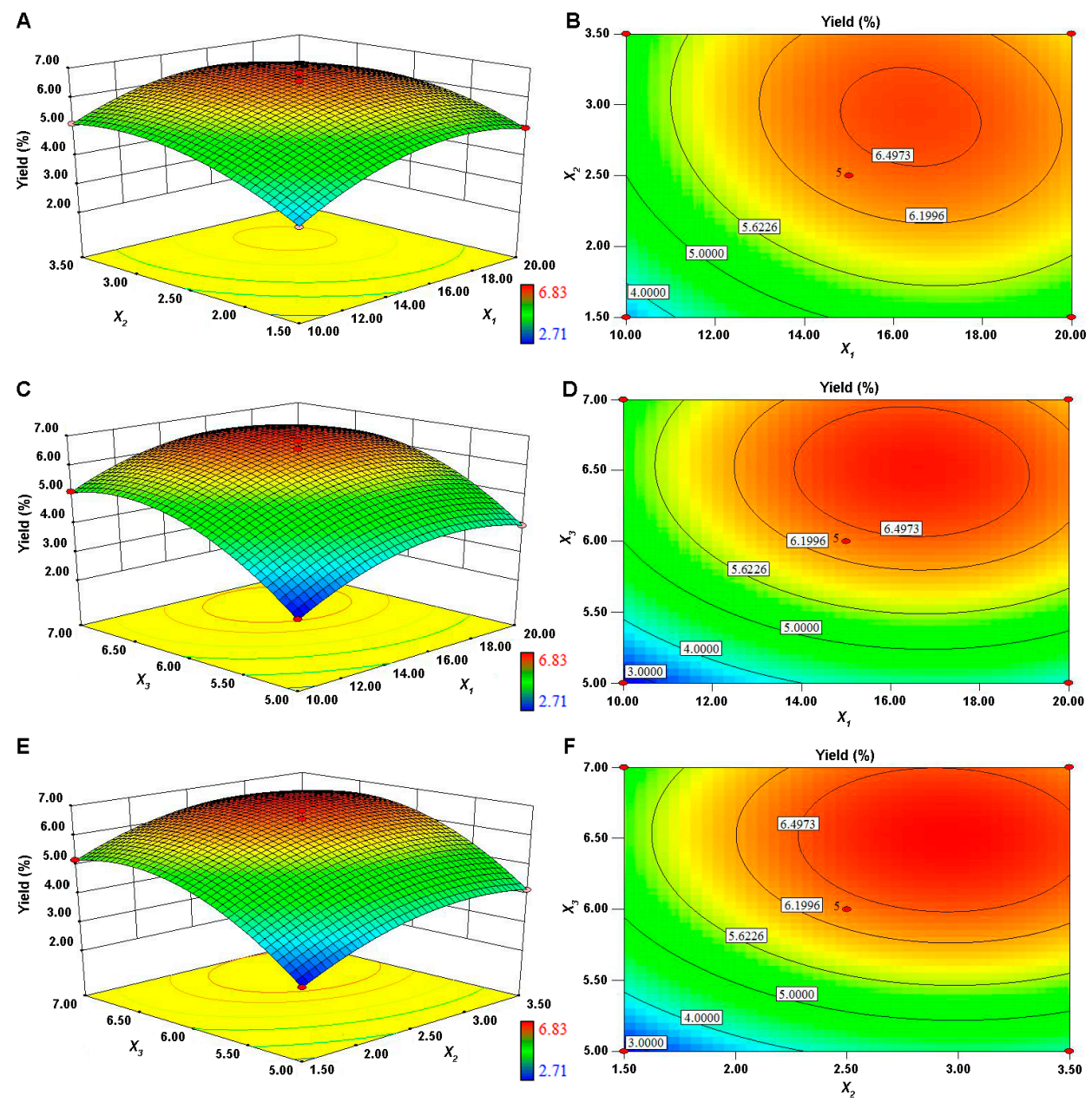

Figure 2. Response surface plots (A, C and E) and contour plots (B, D and F) showing the effects of variables $\left(X_{1}\right.$, ratio of extraction solvent to raw material; $X_{2}$, extraction time; $X_{3}$, extraction $\left.\mathrm{pH}\right)$ and their mutual effects on the extraction yield of PPP.

Based on the single factor experiments and the response surface analysis, the optimal extraction conditions of PPP were concluded as follows: papain concentration of $0.15 \%$, extraction temperature of $50{ }^{\circ} \mathrm{C}$, ratio of extraction solvent to raw material $16.26 \mathrm{~mL} / \mathrm{g}$, extraction time $2.89 \mathrm{~h}$ and extraction $\mathrm{pH}$ 6.83. Under the optimal levels of the extraction variables, the maximum response was $6.83 \%$. A mean 
value of $6.44 \pm 0.06 \%$ ( $n=3$ ) was obtained from real experiments, which was well consistent with the predicted value, and demonstrated the validation of the RSM model for the extraction process. Notably, the yield of PPP was higher than that of some crude polysaccharides $(1.7 \% \sim 4.9 \%)$ from other sea cucumbers $[38,39]$. The optimal extraction conditions of PPP established in this study also require less extraction solvent and extraction time compared with those in some researches $[10,39]$. As stated previously, sea cucumber body wall mainly contains two types of sulfated polysaccharides, i.e., fucosylated glycosaminoglycan and sulfated fucoidan. Therefore, the optimized extraction method may be used for sufficient extraction of polysaccharides from the dried fine powder of other sea cucumber species.

\subsection{Isolation and Characterization of Polysaccharides from PPP}

PPP was prepared using the optimal extraction conditions. Three signal peaks of the extracted polysaccharides were observed in HPGPC spectrum by a Shodex OH-pak SB-806 HQ column (Figure 3). Then, the fractions were separated by an $\mathrm{FPA} 98 \mathrm{Cl}$ column, which afforded two independent elution peaks designated as PPP-1 and PPP-2. The PPP-1 fraction was further separated into two components PPP-1a and PPP-1b by a Sepharose CL-6B column (Figure 3). As shown in Table 4, the residual proteins or polypeptides in PPP can be removed effectively by these columns.

\subsubsection{Homogeneity and Molecular Weights of PPP, PPP-1a, PPP-1b and PPP-2}

The homogeneity and molecular weights of PPP, PPP-1a, PPP-1b and PPP-2 were analyzed by HPLC. As shown in Figure 3a, PPP contained three polysaccharides with different molecular weight ranging from 40 to $400 \mathrm{kDa}$. A single and symmetrical signal peak was observed for each fraction, indicating that they were homogeneous (Figure 3a). The average molecular weights of PPP-1a, PPP-1b and PPP-2 were estimated to be 369.6, 41.73 and $57.76 \mathrm{kDa}$ (Table 4), respectively, according to the calibration curve.

(a)

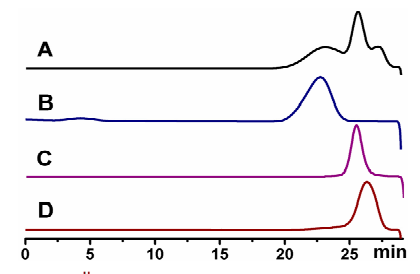

(b)
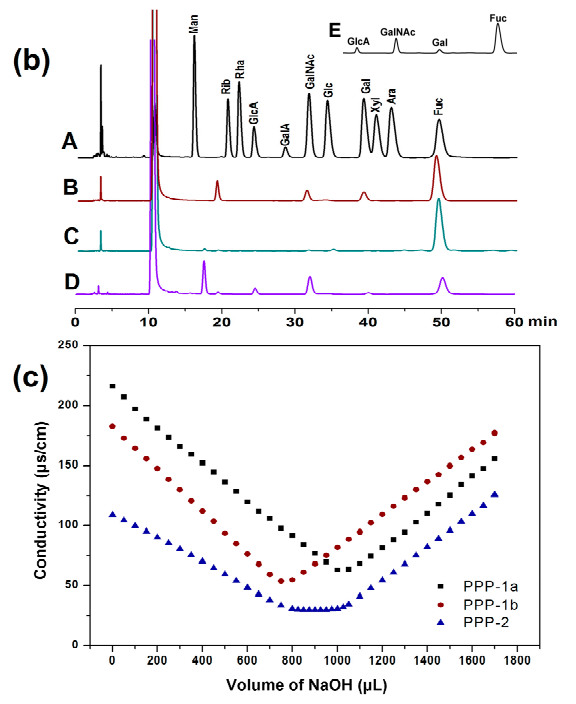

Figure 3. HPLC profiles of PPP (A), PPP-1a (B), PPP-2 (C) and PPP-1b (D) (a), chromatograms of PMP derivatives of mixed monosaccharide standards (A), PPP-1a (B), PPP-1b (C), PPP-2 (D) and PPP (E) (b), and conductimetric titration curves of PPP-1a, PPP-1b and PPP-2 (c). 


\subsubsection{Monosaccharide Composition of PPP, PPP-1a, PPP-1b and PPP-2}

The results of monosaccharide compositions of PPP-1a, PPP-1b and PPP-2 determined by HPLC were showed in Figure $3 b$ and Table 4. It showed that PPP was composed of GlcA, GalNAc, Gal and Fuc with the molar ratio of 1.00:2.34:0.29:9.41, and PPP-1a was composed of GalNAc, Gal and Fuc with the molar ratio of 1.00:1.24:8.04. PPP-1b contained Fuc as the only monosaccharide. PPP-2 was composed of GlcA, GalNAc and Fuc with the molar ratio of 1.00:1.17:1.77. The sulfate contents of PPP, PPP-1a, PPP-1b and PPP-2 were 21.9\%, 20.6\%, 25.2\% and 28.0\%, respectively. PPP-1a and PPP-1b only contained sulfate group, while PPP-2 contained both sulfate and carboxyl groups as shown by the conductometric titration (Figure $3 \mathrm{c}$ and Table 4). These results indicated that PPP, PPP-1a, PPP-1b and PPP-2 were acidic polysaccharides.

Although various sulfated polysaccharides were obtained from some sea cucumber species [22,40], no polysaccharides with similar monosaccharide composition to PPP-1a were reported as far as we know. Moreover, the molecular weight of PPP-1b was significantly lower than those of the fucoidans isolated from other sea cucumber species [13,19,41-43]. Therefore, the sulfated polysaccharides isolated from Phyllophorus proteus may be novel polysaccharides with special structures.

Table 4. Chemical compositions and physicochemical characteristics of PPP, PPP-1a, PPP-1b and PPP-2.

\begin{tabular}{ccccc}
\hline Item & PPP & PPP-1a & PPP-1b & PPP-2 \\
\hline $\begin{array}{c}\text { Molecular weight (kDa) } \\
\text { Monosaccharide composition (mol) }\end{array}$ & $/$ & 369.6 & 41.73 & 57.76 \\
GlcA & 1.00 & $\mathrm{ND}^{\mathrm{a}}$ & $\mathrm{ND}$ & 1.00 \\
GalNAc & 2.34 & 1.00 & $\mathrm{ND}$ & 1.17 \\
Gal & 0.29 & 1.24 & $\mathrm{ND}$ & $\mathrm{ND}$ \\
Fuc & 9.41 & 8.04 & 1.00 & 1.77 \\
Protein content (\%) & 3.62 & 0.14 & 0.01 & 0.02 \\
Sulfate group content (\%) & 21.9 & 20.6 & 25.2 & 28.0 \\
SO $_{3}-/$ COO $^{-}$ & $/$ & $/$ & $/$ & 3.32 \\
Intrinsic viscosity (mL/g) & 106.13 & 172.44 & 62.84 & 39.61 \\
Specific rotation & $-83.22^{\circ}$ & $-77^{\circ}$ & $-138.5^{\circ}$ & $-42.5^{\circ}$ \\
\hline
\end{tabular}

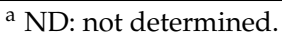

\subsubsection{Specific Rotation, Intrinsic Viscosity and FT-IR Spectrometric Analysis}

The specific rotations of PPP, PPP-1a, PPP-1b and PPP-2 were determined to be $-83.22^{\circ},-77^{\circ}$, $-138.5^{\circ}$ and $-42.5^{\circ}$, respectively (Table 4 ). The data showed that the different types of polysaccharides are all levorotatory, although their specific rotations are different. The strongly negative specific rotations of these polysaccharides may be due to the residues of L-fucopyranose.

Intrinsic viscosity was measured by capillary viscometers of the Ubbelohde type. As shown in Table 4, the intrinsic viscosities [ $\eta$ ] of PPP (106.13) and PPP-1a (172.44) were higher than those of the PPP-1b (62.84) and PPP-2 (39.61), which may due to their relative high molecular weights [9].

The FT-IR spectra of PPP-1a, PPP-1b and PPP-2 were shown in Figure 4A. Broad and strong absorption bands at around $3442 \mathrm{~cm}^{-1}$ assigned for the $\mathrm{C}-\mathrm{H}$ stretching vibrations, $1032 \mathrm{~cm}^{-1}$ for the $\mathrm{C}-\mathrm{O}$ stretching vibrations and $2925 \mathrm{~cm}^{-1}$ for the $\mathrm{C}-\mathrm{H}$ stretching vibrations were observed in the FT-IR spectra of PPP-1a, PPP-1b and PPP-2, respectively. The signal peaks at 1264, 855 and $584 \mathrm{~cm}^{-1}$ were assigned to the $\mathrm{S}=\mathrm{O}$ stretching vibration in sulfate group, $\mathrm{C}-\mathrm{O}-\mathrm{S}$ bending vibration in sulfate group and stretching vibration of $\mathrm{S}-\mathrm{O}$, respectively [44]. The absorption peaks at $1642 \mathrm{~cm}^{-1}$ and $1427 \mathrm{~cm}^{-1}$ for PPP-2 were derived from the stretching vibrations of $\mathrm{C}=\mathrm{O}$ and $\mathrm{COO}-$ in the glucuronic acid, respectively [12,45]. Since PPP-1a and PPP-1b did not contain glucuronic acid, the absorption peak at around $1642 \mathrm{~cm}^{-1}$ may be derived from the stretching vibrations of associated water [46-48]. These signals observed in FT-IR spectra of PPP-1a, PPP-1b and PPP-2 were in agreement with the results of their chemical composition analysis. 


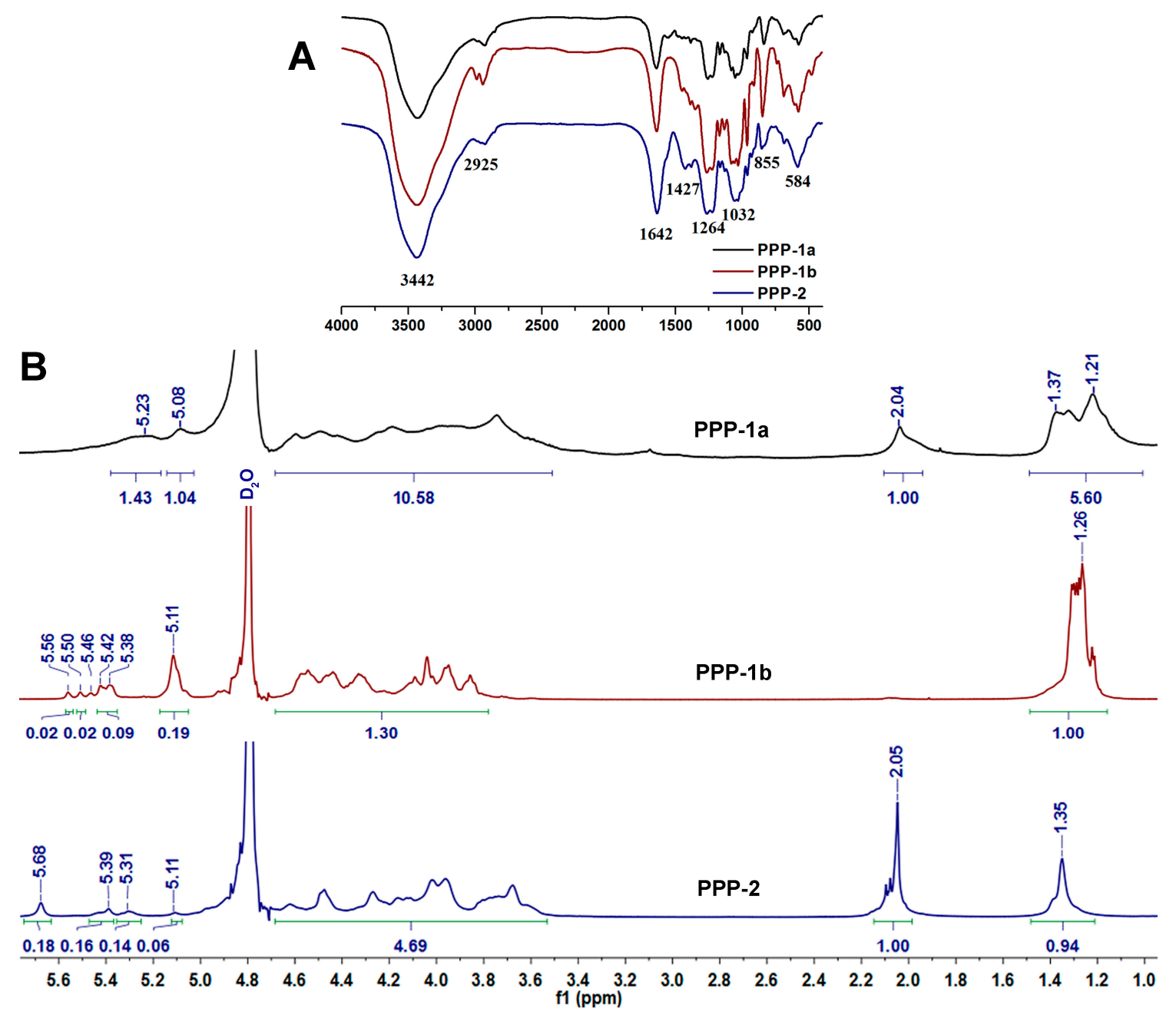

Figure 4. FI-IR (A) and ${ }^{1} \mathrm{H}-\mathrm{NMR}$ (B) spectra of PPP-1a, PPP-1b and PPP-2.

\subsubsection{NMR Analysis of PPP-1a, PPP-1b and PPP-2}

${ }^{1} \mathrm{H}-\mathrm{NMR}$ spectra of PPP-1a, PPP-1b and PPP-2 were showed in Figure 4B. The spectra of the polysaccharides (PPP-1a, PPP-1b and PPP-2) from the sea cucumber Phyllophorus proteus were quite different from each other and all showed a high purity. The signals of PPP- $1 \mathrm{a}$, PPP- $1 \mathrm{~b}$ and PPP- 2 at about 1.2-1.4 ppm and 2.0-2.1 ppm corresponded to the methyl protons of Fuc and GalNAc residues, respectively [27]. The signals at around 3.4-4.6 ppm in spectra of the three polysaccharides can be assigned to the cross ring protons [44,49]. And the chemical shifts of the envelope of anomeric signals of the polysaccharides at 5.0-5.7 ppm were consistent with the presence of $\alpha$-L-fucopyranosyl units $[27,50,51]$. Specifically, anomeric signals at 5.08 and $5.23 \mathrm{ppm}$ in the spectrum of PPP-1a may be assigned to unsulfated and 2-mono-O-sulfo-L-fucopyranosyl residues, respectively, signals at 5.11, 5.38 and $5.56 \mathrm{ppm}$ in the spectrum of PPP- $1 \mathrm{~b}$ may be assigned to unsulfated, 2-mono-O-sulfo- and 2,4-di-O-sulfo-L-fucopyranosyl residues, respectively, and signals at 5.11, 5.31, 5.39 and $5.68 \mathrm{ppm}$ in the spectrum of PPP-2 may be assigned to unsulfated, 4-mono-O-sulfo-, 3-mono-O-sulfo- and 2,4-di-O-sulfo-L-fucopyranosyl residues, respectively [27,41,52]. No signals were observed at about 2.0-2.1 ppm in the spectrum of PPP- $1 \mathrm{~b}$, indicating that PPP- $1 \mathrm{~b}$ contained no GalNAc residue. These NMR results were consistent with those of their monosaccharide composition analysis. The NMR analysis of PPP-1a, PPP-1b and PPP-2 showed overlapping spectra with broad signals, which hamper precise resolution, as expected for polysaccharides of high molecular mass. In our previous studies, the precise structures of a fucosylated glycosaminoglycan and a sulfated fucan 
from Stichopus variegatus and Ludwigothurea grisea, respectively, have been elucidated by analyzing the structures of their depolymerized products, which contain the repeating trisaccharide unit - $\{(\mathrm{L}-$ Fuc- $\alpha 1,3-)$ D-GlcA- $\beta 1,3-\mathrm{D}-$ GalNAc- $\beta 1,4-\}$ - and the regular $(1 \rightarrow 2)$ and $(1 \rightarrow 3)$-linked tetrasaccharide repeating unit, respectively $[10,12]$. In the present study, PPP-1a, PPP-1b and PPP-2 had obviously different ${ }^{1} \mathrm{H}$-NMR spectra from those of the previously reported polysaccharides from other species of sea cucumbers $[10,12,27,41,44]$. The structures of these polysaccharides may be also elucidated by using the depolymerization methods $[10,12]$. The detailed structures of these polysaccharides will be studied in the near future.

\subsection{In Vitro Antioxidant Activity of PPP}

\subsubsection{DPPH Radical Scavenging Activity}

The assay of DPPH free radical scavenging has been widely used to evaluate the antioxidant activity of natural compounds for its simple, sensitivity, comparable and reproducible operation $[53,54]$. Antioxidant such as Vc can scavenge DPPH radical by donating a hydrogen to form the stable DPPH-H molecules. It has been reported that the antioxidant activity of polysaccharides was related to electron-withdrawing carboxyl or acetyl groups, which could activate the hydrogen atom of the sugar residues through field and inductive effects [55]. As shown in Figure 5A, PPP, PPP-1a, PPP-1b and PPP-2 all exhibited does-dependently DPPH scavenging activity. At a concentration of $4.0 \mathrm{mg} / \mathrm{mL}$, the DPPH free radical scavenging rates were $33.07 \%, 26.22 \%, 16.89 \%, 30.90 \%$ and $87.83 \%$ for PPP, PPP-1a, PPP-1b, PPP-2 and Vc, respectively. In the test ranges, DPPH scavenging activities of PPP, PPP-1a and PPP-2 were significantly higher $(p<0.05)$ than that of PPP-1b, which may be due to the carboxyl or acetyl group contents. Proteins or polypeptides in PPP may also increase its scavenging effect on DPPH for these molecules also showed good antioxidant activities [56].
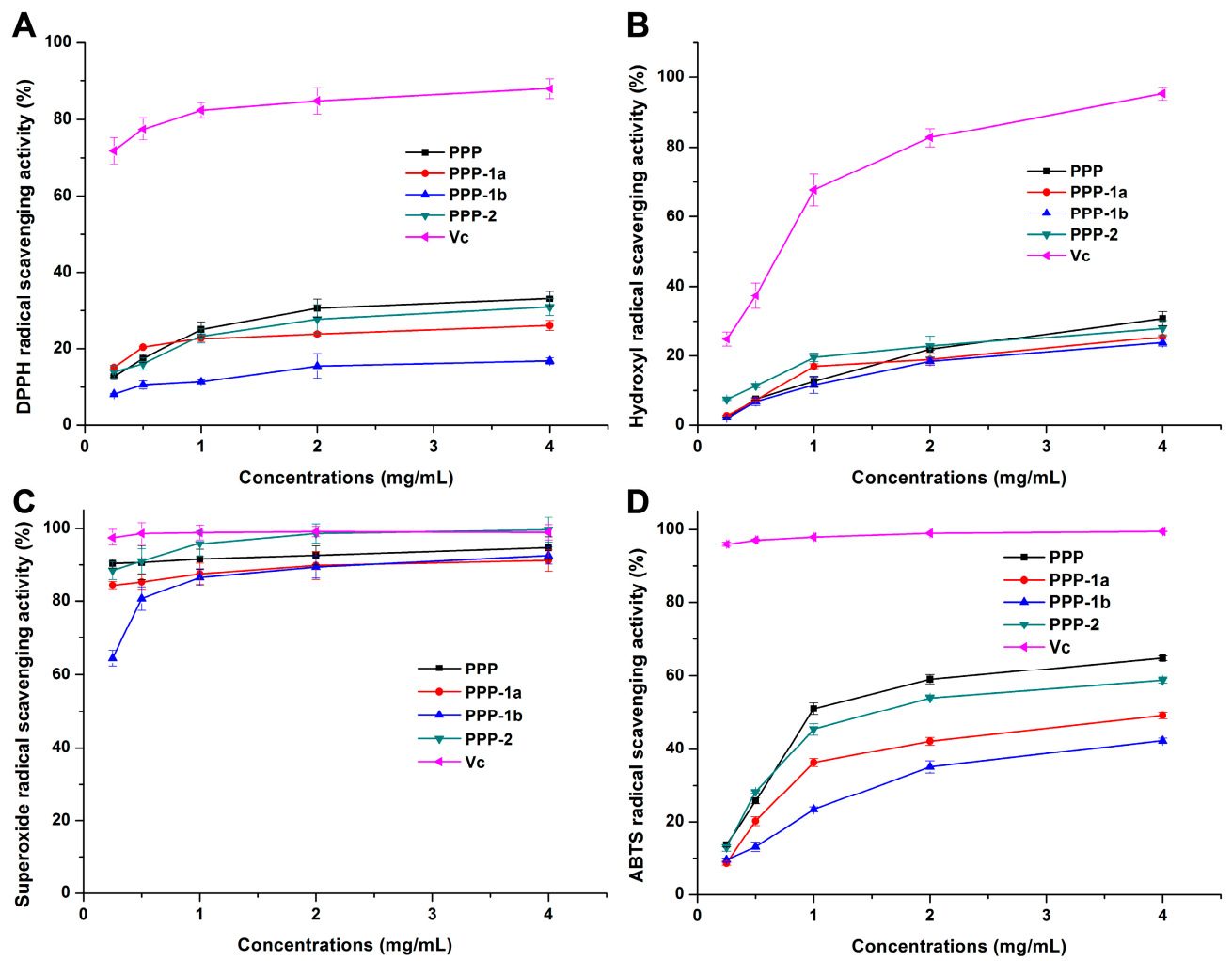

Figure 5. Scavenging effects of PPP, PPP-1a, PPP-1b and PPP-2 on DPPH radical (A), hydroxyl radical (B), superoxide radical (C) and ABTS radical (D), respectively. 


\subsubsection{Hydroxyl Radical Scavenging Activity}

The effects of PPP, PPP-1a, PPP-1b or PPP-2 on the hydroxyl radical scavenging were detected and compared with the positive control Vc. The result showed that they displayed the activity at a concentration-dependent manner (Figure 5B). At a concentration of $4.0 \mathrm{mg} / \mathrm{mL}$, the hydroxyl radical scavenging rates of PPP, PPP-1a, PPP-1b, PPP-2 and Vc were $30.76 \%, 25.41 \%, 23.72 \%, 27.99 \%$ and 95.14\%, respectively, and PPP and PPP-2 had slightly higher activities than those of PPP-1a and PPP- $1 b$ (Figure 5B). Hydroxyl radicals are speculated to be generated from the $\mathrm{Fe}^{2+} / \mathrm{H}_{2} \mathrm{O}_{2}$ Fenton reaction system [57]. Previous studies have suggested that hydroxyl radical scavenging activity of polysaccharides may be due to inhibition of hydroxyl radical generation by chelating $\mathrm{Fe}^{2+}$ ions [58]. In this study, carboxyl and sulfate groups in PPP, PPP-1a, PPP-1b and PPP-2 are highly nucleophilic and may chelate with $\mathrm{Fe}^{2+}$ ions. Consequently, the slightly higher hydroxyl radical scavenging activities of PPP and PPP-2 may be due to their higher content of uronic acid.

\subsubsection{Superoxide Radical Scavenging Activity}

Superoxide anion can induce lipid peroxidation for it is one of the precursors of the hydroxyl radical and singlet oxygen, which cause oxidative damage to proteins, DNA and enzymes in vivo. Superoxide anion can also magnify the cellular damage and further exacerbate the progression of many diseases including atherosclerosis and arthritis by producing other types of free radicals and oxidizing agents [55]. The superoxide radical scavenging activities of polysaccharide samples were detected and compared with that of $\mathrm{Vc}$. Scavenging effects of samples against superoxide radical were positively correlated with their concentration in the range of $0.25-4.0 \mathrm{mg} / \mathrm{mL}$ (Figure 5C). The superoxide radical scavenging rates of PPP, PPP-1a, PPP- $1 \mathrm{~b}$, PPP- 2 and $\mathrm{Vc}$ at $0.25 \mathrm{mg} / \mathrm{mL}$ were high as $90.32 \%, 84.39 \%$, $64.57 \%, 88.44 \%$ and $97.50 \%$, respectively. At the high concentration of $4.0 \mathrm{mg} / \mathrm{mL}$, the superoxide radical scavenging rates of PPP, PPP-1a, PPP- $1 b$, PPP-2 and $V_{c}$ reached to $94.55 \%, 91.15 \%, 92.47 \%$, $99.66 \%$ and $98.98 \%$, respectively, and the scavenging rates of PPP and PPP-2 showed no significant differences $(p>0.05)$ compared with that of Vc. The mechanism of superoxide radical scavenging activities may be related to the dissociation energy of $\mathrm{O}-\mathrm{H}$ bond [59]. There was evidence that the presence of sulfate group in polysaccharides could enhance the superoxide radical scavenging activities due to the increase of electron-donating substituents in a saccharide ring, thus increasing electron density of the carbon atoms in the saccharide ring and facilitating liberation of hydrogen from $\mathrm{O}-\mathrm{H}$ bond to stabilize superoxide anion $[55,60]$. In our present study, all the acidic polysaccharides showed strong superoxide radical scavenging activity, which is accordant with the results of the synthesized oversulphated derivatives of fucoidan extracted from Laminaria japonica [55]. The PPP and PPP-2 containing higher uronic acid also showed higher superoxide radical scavenging activity compared with PPP-1a and PPP-1b which contain no uronic acid, consisting with previous reports [61]. The effects of sulfate and carboxyl groups may be further confirmed by the desulfated and carboxyl-reduced derivatives of these polysaccharides in the future study, referring to our previous study [62].

\subsubsection{ABTS Radical Scavenging Activity}

The assay of ABTS radical scavenging activity is commonly used in determining the total antioxidant activity of polysaccharides from natural products $[34,63,64]$. Herein, the results showed that ABTS radical scavenging activities of PPP, PPP- $1 \mathrm{a}$, PPP- $1 \mathrm{~b}$ and PPP-2 enhanced as their concentration increased (Figure 5D). Among the samples, the ABTS radical scavenging activity was determined to be in the order of PPP $>$ PPP-2 $>$ PPP- $1 \mathrm{a}>$ PPP- $1 \mathrm{~b}$. Particularly, at the concentration of $4.0 \mathrm{mg} / \mathrm{mL}$, the scavenging rates of PPP, PPP-1a, PPP- $1 \mathrm{~b}$, PPP-2 and Vc were $64.91 \%, 49.12 \%, 42.33 \%$, $58.84 \%$ and $99.52 \%$, respectively. And notably, PPP and PPP-2 had higher scavenging rates than PPP- $1 \mathrm{a}$ and PPP- $1 \mathrm{~b}(p<0.05)$. The results indicated that antioxidant activities of the polysaccharides determined by ABTS assay were positively correlated to those obtained by the DPPH radical assay, and that the scavenging ability obtained by ABTS assay was higher than that by DPPH radical 
assay. The ABTS assay may be more suitable than DPPH assay for evaluating the high water-soluble polysaccharides $[15,65]$.

\section{Conclusions}

The extraction conditions for PPP were optimized by RSM with a BBD design in the present study. An extraction yield of $6.44 \pm 0.06 \%$ was obtained by the optimal extraction conditions: ratio of water to raw material of $16.26 \mathrm{~mL} / \mathrm{g}$, extraction time of $2.89 \mathrm{~h}$, extraction $\mathrm{pH}$ of 6.83 , temperature of $50{ }^{\circ} \mathrm{C}$ and papain concentration of $0.15 \%$. Three fractions of polysaccharides PPP- $1 \mathrm{a}$, PPP- $1 \mathrm{~b}$ and PPP- 2 with the average molecular weights of $369.6,41.73$ and $57.76 \mathrm{kDa}$, respectively, were obtained from PPP by chromatography of FPA98Cl and Sepharose CL-6B columns. Further analysis showed that PPP-1a was composed of GalNAc, Gal and Fuc with Fuc as the main monosaccharide, PPP-1b contained Fuc as the only monosaccharide, and PPP-2 was composed of GlcA, GalNAc and Fuc with a nearly equal molar ratio. The sulfate contents of PPP, PPP-1a, PPP- $1 \mathrm{~b}$ and PPP-2 were $21.9 \%, 20.6 \%, 25.2 \%$ and $28.0 \%$, respectively. The chemical analysis results along with the FT-IR spectra demonstrated that PPP, PPP-1a, PPP- $1 b$ and PPP- 2 were all acidic polysaccharides. Furthermore, PPP, PPP- $1 \mathrm{a}$, PPP- $1 \mathrm{~b}$ and PPP-2 showed obvious scavenging activity of superoxide radical, DPPH radical, hydroxyl radical, and ABTS radical, which may be closely related to their structures such as monosaccharide compositions, and contents of carboxyl and sulfate groups. The results suggested that polysaccharides from sea cucumber Phyllophorus proteus may have protective effects as a potent antioxidant, which may provide valuable information for further research, enlarge the knowledge of sea cucumber polysaccharides.

Acknowledgments: We thank Zhenghui Li and Yanling Yang in the Analytical \& Measuring Center, School of Pharmaceutical Sciences, South-Central University for Nationalities for performing the NMR experiments. This work was supported by the National Natural Science Foundation of China (Nos. 31600649, 81373292), the Key Projects of Technological Innovation of Hubei Province (No. 2016ACA138) and the Technology Program of Guangdong Province (Nos. 2017A040405060, 2015A030302089).

Author Contributions: Lo.Z., J.Z. and J. Liu conceived and designed the experiments; Y.Q., Q.Y., Y.Z., J. Li, X.Z., Li.Z., and J.W. performed the experiments; Q.Y. and Lo.Z. analyzed the data; J.Z. contributed reagents/materials/analysis tools; Q.Y. and Lo.Z. wrote the paper.

Conflicts of Interest: The authors declare no conflict of interest.

\section{References}

1. Barnes, A.T.; Quetin, L.B.; Childress, J.J.; Pawson, D.L. Deep-sea macroplanktonic sea cucumbers: suspended sediment feeders captured from deep submergence vehicle. Science 1976, 194, 1083-1085. [CrossRef] [PubMed]

2. Liu, X.; Liu, Y.; Hao, J.; Zhao, X.; Lang, Y.; Fan, F.; Cai, C.; Li, G.; Zhang, L.; Yu, G. In Vivo anti-cancer mechanism of low-molecular-weight fucosylated chondroitin sulfate (LFCS) from sea cucumber Cucumaria frondosa. Molecules 2016, 21, 625. [CrossRef] [PubMed]

3. Wu, Z.; Chen, H.; Wang, W.; Jia, B.; Yang, T.; Zhao, Z.; Ding, J.; Xiao, X. Differentiation of dried sea cucumber products from different geographical areas by surface desorption atmospheric pressure chemical ionization mass spectrometry. J. Agric. Food Chem. 2009, 57, 9356-9364. [CrossRef] [PubMed]

4. Cao, R.A.; Surayot, U.; You, S.G. Structural characterization of immunostimulating protein-sulfated fucan complex extracted from the body wall of a sea cucumber, Stichopus japonicus. Int. J. Biol. Macromol. 2017, 99, 539-548. [CrossRef] [PubMed]

5. Wei, C.Y.; Liao, N.B.; Zhang, Y.; Ye, X.Q.; Li, S.; Hu, Y.Q.; Liu, D.H.; Linhardt, R.J.; Wang, X.; Chen, S.G. In vitro fermentation behaviors of fucosylated chondroitin sulfate from Pearsonothuria graeffei by human gut microflora. Int. J. Biol. Macromol. 2017, 102, 1195-1201. [CrossRef] [PubMed]

6. Silchenko, A.; Kalinovsky, A.; Avilov, S.; Andryjaschenko, P.; Dmitrenok, P.; Kalinin, V.; Chingizova, E.; Minin, K.; Stonik, V. Structures and biogenesis of fallaxosides D4, D5, D6 and D7, trisulfated non-holostane triterpene glycosides from the sea cucumber Cucumaria fallax. Molecules 2016, 21, 939. [CrossRef] [PubMed] 
7. Duan, J.; Ishida, M.; Aida, K.; Tsuduki, T.; Zhang, J.; Manabe, Y.; Hirata, T.; Sugawara, T. Dietary cerebroside from sea cucumber (Stichopus japonicus): Absorption and effects on skin barrier and cecal short-chain fatty acids. J. Agric. Food Chem. 2016, 64, 7014-7021. [CrossRef] [PubMed]

8. He, L.-X.; Zhang, Z.-F.; Sun, B.; Chen, Q.-H.; Liu, R.; Ren, J.-W.; Wang, J.-B.; Li, Y. Sea cucumber (Codonopsis pilosula) oligopeptides: Immunomodulatory effects based on stimulating Th cells, cytokine secretion and antibody production. Food Funct. 2016, 7, 1208-1216. [CrossRef] [PubMed]

9. Luo, L.; Wu, M.; Xu, L.; Lian, W.; Xiang, J.; Lu, F.; Gao, N.; Xiao, C.; Wang, S.; Zhao, J. Comparison of physicochemical characteristics and anticoagulant activities of polysaccharides from three sea cucumbers. Mar. Drugs 2013, 11, 399-417. [CrossRef] [PubMed]

10. Wu, M.; Xu, L.; Zhao, L.; Xiao, C.; Gao, N.; Luo, L.; Yang, L.; Li, Z.; Chen, L.; Zhao, J. Structural analysis and anticoagulant activities of the novel sulfated fucan possessing a regular well-defined repeating unit from sea cucumber. Mar. Drugs 2015, 13, 2063-2084. [CrossRef] [PubMed]

11. Myron, P.; Siddiquee, S.; Al Azad, S. Fucosylated chondroitin sulfate diversity in sea cucumbers: A review. Carbohydr. Polym. 2014, 112, 173-178. [CrossRef] [PubMed]

12. Zhao, L.; Wu, M.; Xiao, C.; Yang, L.; Zhou, L.; Gaoa, N.; Li, Z.; Chen, J.; Chen, J.; Liu, J.; Qin, H.; Zhao, J. Discovery of an intrinsic tenase complex inhibitor: Pure nonasaccharide from fucosylated glycosaminoglycan. Proc. Natl. Acad. Sci. USA 2015, 112, 8284-8289. [CrossRef] [PubMed]

13. Chen, S.; Hu, Y.; Ye, X.; Li, G.; Yu, G.; Xue, C.; Chai, W. Sequence determination and anticoagulant and antithrombotic activities of a novel sulfated fucan isolated from the sea cucumber Isostichopus badionotus. Biochim. Biophys. BBA Gen. Subj. 2012, 1820, 989-1000. [CrossRef] [PubMed]

14. Pomin, V.H. Holothurian fucosylated chondroitin sulfate. Mar. Drugs 2014, 12, 232-254. [CrossRef] [PubMed]

15. Yuan, Q.; Xie, Y.; Wang, W.; Yan, Y.; Ye, H.; Jabbar, S.; Zeng, X. Extraction optimization, characterization and antioxidant activity in vitro of polysaccharides from mulberry (Morus alba L.) leaves. Carbohydr. Polym. 2015, 128, 52-62. [CrossRef] [PubMed]

16. Wang, L.; Wang, G.; Zhang, J.; Zhang, G.; Jia, L.; Liu, X.; Deng, P.; Fan, K. Extraction optimization and antioxidant activity of intracellular selenium polysaccharide by Cordyceps sinensis SU-02. Carbohydr. Polym. 2011, 86, 1745-1750. [CrossRef]

17. Zhu, Y.; Li, Q.; Mao, G.; Zou, Y.; Feng, W.; Zheng, D.; Wang, W.; Zhou, L.; Zhang, T.; Yang, J.; et al. Optimization of enzyme-assisted extraction and characterization of polysaccharides from Hericium erinaceus. Carbohydr. Polym. 2014, 101, 606-613. [CrossRef] [PubMed]

18. Wu, N.; Zhang, Y.; Ye, X.; Hu, Y.; Ding, T.; Chen, S. Sulfation pattern of fucose branches affects the anti-hyperlipidemic activities of fucosylated chondroitin sulfate. Carbohydr. Polym. 2016, 147, 1-7. [CrossRef] [PubMed]

19. Li, S.; Li, J.; Zhi, Z.; Wei, C.; Wang, W.; Ding, T.; Ye, X.; Hu, Y.; Linhardt, R.J.; Chen, S. Macromolecular properties and hypolipidemic effects of four sulfated polysaccharides from sea cucumbers. Carbohydr. Polym. 2017, 173, 330-337. [CrossRef] [PubMed]

20. Esmat, A.Y.; Said, M.M.; Soliman, A.A.; El-Masry, K.S.H.; Badiea, E.A. Bioactive compounds, antioxidant potential, and hepatoprotective activity of sea cucumber (Holothuria atra) against thioacetamide intoxication in rats. Nutrition 2013, 29, 258-267. [CrossRef] [PubMed]

21. Mena-Bueno, S.; Atanasova, M.; Fernández-Trasancos, Á.; Paradela-Dobarro, B.; Bravo, S.B.; Álvarez, E.; Fernández, Á.L.; Carrera, I.; González-Juanatey, J.R.; Eiras, S. Sea cucumbers with an anti-inflammatory effect on endothelial cells and subcutaneous but not on epicardial adipose tissue. Food Funct. 2016, 7, 953-963. [CrossRef] [PubMed]

22. Liu, X.; Sun, Z.; Zhang, M.; Meng, X.; Xia, X.; Yuan, W.; Xue, F.; Liu, C. Antioxidant and antihyperlipidemic activities of polysaccharides from sea cucumber Apostichopus japonicus. Carbohydr. Polym. 2012, 90, 1664-1670. [CrossRef] [PubMed]

23. Wen, J.; Hu, C.; Zhang, L.; Fan, S. Genetic identification of global commercial sea cucumber species on the basis of mitochondrial DNA sequences. Food Control 2011, 22, 72-77. [CrossRef]

24. Dubois, M.; Gilles, K.A.; Hamilton, J.K.; Rebers, P.A.; Smith, F. Colorimetric Method for Determination of Sugars and Related Substances. Anal. Chem. 1956, 28, 350-356. [CrossRef]

25. Saito, H.; Yamagata, T.; Suzuki, S. Enzymatic methods for the determination of small quantities of isomeric chondroitin sulfates. J. Biol. Chem. 1968, 243, 1536-1542. [PubMed] 
26. Casu, B.; Gennaro, U. A conductimetric method for the determination of sulphate and carboxyl groups in heparin and other mucopolysaccharides. Carbohydr. Res. 1975, 39, 168-176. [CrossRef]

27. Zhao, L.; Lai, S.; Huang, R.; Wu, M.; Gao, N.; Xu, L.; Qin, H.; Peng, W.; Zhao, J. Structure and anticoagulant activity of fucosylated glycosaminoglycan degraded by deaminative cleavage. Carbohydr. Polym. 2013, 98, 1514-1523. [CrossRef] [PubMed]

28. Yang, L.; Fu, S.; Zhu, X.; Zhang, L.M.; Yang, Y.; Yang, X.; Liu, H. Hyperbranched acidic polysaccharide from green tea. Biomacromolecules 2010, 11, 3395-3405. [CrossRef] [PubMed]

29. Shimada, K.; Fujikawa, K.; Yahara, K.; Nakamura, T. Antioxidative properties of xanthan on the autoxidation of soybean oil in cyclodextrin emulsion. J. Agric. Food Chem. 1992, 40, 945-948. [CrossRef]

30. Liu, J.; Jia, L.; Kan, J.; Jin, C. hai In vitro and in vivo antioxidant activity of ethanolic extract of white button mushroom (Agaricus bisporus). Food Chem. Toxicol. 2013, 51, 310-316. [CrossRef] [PubMed]

31. Luo, A.; He, X.; Zhou, S.; Fan, Y.; Luo, A.; Chun, Z. Purification, composition analysis and antioxidant activity of the polysaccharides from Dendrobium nobile Lindl. Carbohydr. Polym. 2010, 79, 1014-1019. [CrossRef]

32. Bi, H.; Gao, T.; Li, Z.; Ji, L.; Yang, W.; Jeff Iteku, B.; Liu, E.; Zhou, Y. Structural elucidation and antioxidant activity of a water-soluble polysaccharide from the fruit bodies of Bulgaria inquinans (Fries). Food Chem. 2013, 138, 1470-1475. [CrossRef] [PubMed]

33. Re, R.; Pellegrini, N.; Proteggente, A.; Pannala, A.; Yang, M.; Rice-Evans, C. Antioxidant activity applying an improved ABTS radical cation decolorization assay. Free Radic. Biol. Med. 1999, 26, 1231-1237. [CrossRef]

34. Liu, Y.; Zhang, B.; Ibrahim, S.A.; Gao, S.S.; Yang, H.; Huang, W. Purification, characterization and antioxidant activity of polysaccharides from Flammulina velutipes residue. Carbohydr. Polym. 2016, 145, 71-77. [CrossRef] [PubMed]

35. Chen, H.; Zhou, X.; Zhang, J. Optimization of enzyme assisted extraction of polysaccharides from Astragalus membranaceus. Carbohydr. Polym. 2014, 111, 567-575. [CrossRef] [PubMed]

36. Li, H.; Yuan, Q.; Zhou, X.; Zeng, F.; Lu, X. Extraction of Opuntia dillenii Haw. polysaccharides and their antioxidant activities. Molecules 2016, 21, 1612. [CrossRef] [PubMed]

37. Zhu, C.P.; Zhai, X.C.; Li, L.Q.; Wu, X.X.; Li, B. Response surface optimization of ultrasound-assisted polysaccharides extraction from pomegranate peel. Food Chem. 2015, 177, 139-146. [CrossRef] [PubMed]

38. Ustyuzhanina, N.E.; Bilan, M.I.; Dmitrenok, A.S.; Tsvetkova, E.A.; Shashkov, A.S.; Stonik, V.A.; Nifantiev, N.E.; Usov, A.I. Structural characterization of fucosylated chondroitin sulfates from sea cucumbers Apostichopus japonicus and Actinopyga mauritiana. Carbohydr. Polym. 2016, 153, 399-405. [CrossRef] [PubMed]

39. Ustyuzhanina, N.E.; Bilan, M.I.; Dmitrenok, A.S.; Shashkov, A.S.; Nifantiev, N.E.; Usov, A.I. The structure of a fucosylated chondroitin sulfate from the sea cucumber Cucumaria frondosa. Carbohydr. Polym. 2017, 165, 7-12. [CrossRef] [PubMed]

40. Wang, Y.; Wang, J.; Zhao, Y.; Hu, S.; Shi, D.; Xue, C. Fucoidan from sea cucumber Cucumaria frondosa exhibits anti-hyperglycemic effects in insulin resistant mice via activating the PI3K/PKB pathway and GLUT4. J. Biosci. Bioeng. 2016, 121, 36-42. [CrossRef] [PubMed]

41. Guo, X.; Ye, X.; Sun, Y.; Wu, D.; Wu, N.; Hu, Y.; Chen, S. Ultrasound effects on the degradation kinetics, structure, and antioxidant activity of sea cucumber fucoidan. J. Agric. Food Chem. 2014, 62, 1088-1095. [CrossRef] [PubMed]

42. Wang, Y.; Su, W.; Zhang, C.; Xue, C.; Chang, Y.; Wu, X.; Tang, Q.; Wang, J. Protective effect of sea cucumber (Acaudina molpadioides) fucoidan against ethanol-induced gastric damage. Food Chem. 2012, 133, 1414-1419. [CrossRef]

43. Yu, L.; Xue, C.; Chang, Y.; Xu, X.; Ge, L.; Liu, G.; Wang, Y. Structure elucidation of fucoidan composed of a novel tetrafucose repeating unit from sea cucumber Thelenota ananas. Food Chem. 2014, 146, 113-119. [CrossRef] [PubMed]

44. Wu, N.; Ye, X.; Guo, X.; Liao, N.; Yin, X.; Hu, Y.; Sun, Y.; Liu, D.; Chen, S. Depolymerization of fucosylated chondroitin sulfate from sea cucumber, Pearsonothuria graeffei, via 60Co irradiation. Carbohydr. Polym. 2013, 93, 604-614. [CrossRef] [PubMed]

45. Wu, M.; Xu, S.; Zhao, J.; Kang, H.; Ding, H. Physicochemical characteristics and anticoagulant activities of low molecular weight fractions by free-radical depolymerization of a fucosylated chondroitin sulphate from sea cucumber Thelenata ananas. Food Chem. 2010, 122, 716-723. [CrossRef] 
46. You, L.; Gao, Q.; Feng, M.; Yang, B.; Ren, J.; Gu, L.; Cui, C.; Zhao, M. Structural characterisation of polysaccharides from Tricholoma matsutake and their antioxidant and antitumour activities. Food Chem. 2013, 138, 2242-2249. [CrossRef] [PubMed]

47. Zhao, G.; Kan, J.; Li, Z.; Chen, Z. Structural features and immunological activity of a polysaccharide from Dioscorea opposita Thunb roots. Carbohydr. Polym. 2005, 61, 125-131. [CrossRef]

48. Ding, X.; Feng, S.; Cao, M.; Li, M.T.; Tang, J.; Guo, C.X.; Zhang, J.; Sun, Q.; Yang, Z.R.; Zhao, J. Structure characterization of polysaccharide isolated from the fruiting bodies of Tricholoma matsutake. Carbohydr. Polym. 2010, 81, 942-947. [CrossRef]

49. Yoshida, K.-I.; Minami, Y.; Nemoto, H.; Numata, K.; Yamanaka, E. Structure of DHG, a depolymerized glycosaminoglycan from sea cucumber, Stichopus japonicus. Tetrahedron Lett. 1992, 33, 4959-4962. [CrossRef]

50. Panagos, C.G.; Thomson, D.S.; Moss, C.; Hughes, A.D.; Kelly, M.S.; Liu, Y.; Chai, W.; Venkatasamy, R.; Spina, D.; Page, C.P.; et al. Fucosylated chondroitin sulfates from the body wall of the sea cucumber Holothuria forskali: Conformation, selectin binding, and biological activity. J. Biol. Chem. 2014, 289, 28284-28298. [CrossRef] [PubMed]

51. Mulloy, B.; Ribeiro, A.C.; Alves, A.P.; Vieira, R.P.; Mourão, P.A.S. Sulfated fucans from echinoderms have a regular tetrasaccharide repeating unit defined by specific patterns of sulfation at the O-2 and O-4 positions. J. Biol. Chem. 1994, 269, 22113-22123. [PubMed]

52. Tako, M.; Nakada, T.; Hongou, F. Chemical characterization of fucoidan from commercially cultured Nemacystus decipiens (Itomozuku). Biosci. Biotechnol. Biochem. 1999, 63, 1813-1815. [CrossRef] [PubMed]

53. Sánchez-Moreno, C. Review: Methods used to evaluate the free radical sacavening activity in foods and biological systems. Food Sci. Technol. Int. 2002, 8, 121-137. [CrossRef]

54. Zhao, Y.; Du, S.K.; Wang, H.; Cai, M. In vitro antioxidant activity of extracts from common legumes. Food Chem. 2014, 152, 462-466. [CrossRef] [PubMed]

55. Wang, J.; Liu, L.; Zhang, Q.; Zhang, Z.; Qi, H.; Li, P. Synthesized oversulphated, acetylated and benzoylated derivatives of fucoidan extracted from Laminaria japonica and their potential antioxidant activity in vitro. Food Chem. 2009, 114, 1285-1290. [CrossRef]

56. Bordbar, S.; Anwar, F.; Saari, N. High-value components and bioactives from sea cucumbers for functional foods-A review. Mar. Drugs 2011, 9, 1761-1805. [CrossRef] [PubMed]

57. Liu, C.; Chang, J.; Zhang, L.; Zhang, J.; Li, S. Purification and antioxidant activity of a polysaccharide from bulbs of Fritillaria ussuriensis Maxim. Int. J. Biol. Macromol. 2012, 50, 1075-1080. [CrossRef] [PubMed]

58. Liu, C.; Wang, C.; Xu, Z.; Wang, Y. Isolation, chemical characterization and antioxidant activities of two polysaccharides from the gel and the skin of Aloe barbadensis Miller irrigated with sea water. Process Biochem. 2007, 42, 961-970.

59. Jin, L.; Guan, X.; Liu, W.; Zhang, X.; Yan, W.; Yao, W.; Gao, X. Characterization and antioxidant activity of a polysaccharide extracted from Sarcandra glabra. Carbohydr. Polym. 2012, 90, 524-532. [CrossRef] [PubMed]

60. Xie, J.H.; Wang, Z.J.; Shen, M.Y.; Nie, S.P.; Gong, B.; Li, H.S.; Zhao, Q.; Li, W.J.; Xie, M.Y. Sulfated modification, characterization and antioxidant activities of polysaccharide from Cyclocarya paliurus. Food Hydrocoll. 2016, 53, 7-15. [CrossRef]

61. Sun, Y.X.; Liu, J.C.; Kennedy, J.F. Purification, composition analysis and antioxidant activity of different polysaccharide conjugates (APPs) from the fruiting bodies of Auricularia polytricha. Carbohydr. Polym. 2010, 82, 299-304. [CrossRef]

62. Zhao, L.; Qin, Y.; Guan, R.; Zheng, W.; Liu, J.; Zhao, J. Digestibility of fucosylated glycosaminoglycan from sea cucumber and its effects on digestive enzymes under simulated salivary and gastrointestinal conditions. Carbohydr. Polym. 2018, 186, 217-225. [CrossRef] [PubMed]

63. Zou, S.; Pan, R.; Dong, X.; He, M.; Wang, C. Physicochemical properties and antioxidant activities of two fucosylated chondroitin sulfate from sea cucumber Acaudina molpadioidea and Holothuria nobilis. Process Biochem. 2016, 51, 650-658. [CrossRef] 
64. Zhang, H.; Ma, H.; Liu, W.; Pei, J.; Wang, Z.; Zhou, H.; Yan, J. Ultrasound enhanced production and antioxidant activity of polysaccharides from mycelial fermentation of Phellinus igniarius. Carbohydr. Polym. 2014, 113, 380-387. [CrossRef] [PubMed]

65. Floegel, A.; Kim, D.O.; Chung, S.J.; Koo, S.I.; Chun, O.K. Comparison of ABTS/DPPH assays to measure antioxidant capacity in popular antioxidant-rich US foods. J. Food Compos. Anal. 2011, 24, 1043-1048. [CrossRef]

Sample Availability: Samples of the compounds PPP, PPP-1a, PPP-1b and PPP-2 are available from the authors.

(C) 2018 by the authors. Licensee MDPI, Basel, Switzerland. This article is an open access article distributed under the terms and conditions of the Creative Commons Attribution (CC BY) license (http:/ / creativecommons.org/licenses/by/4.0/). 